\title{
السكك الحديدية السورية \\ دراسة مقارنة مع شبكات السكك العربية والعالمية
}

$$
\text { د.م. شفيق عباس داؤد }
$$

\begin{abstract}
Syria is potentially an ideal country for railway operations. A large proportion of the population and economic activities is concentrated on a North - South and east - west axis. The distances between major cities are generally those for which rail is most competitive on inter-city passenger and freight transport services.
\end{abstract}

The railway network services connect:

- Production centers with consumption centers (domestic transport).

- Production centers with export gates to Iraq, Turkey, Ports of Tartous and Lattakia and Syrian Free Zones.

- Consumption and manufacturing centers with import gates (Iraq, Turkey, Ports of Tartous and Lattakia).

- Transit corridors particularly the north-south corridor from Turkey (and beyond) to Iraq and west-east corridor from the Syrian Ports to Iraq (2 directions for both corridors).

- In the future, Jordan and Lebanon will be connected to the Syrian Railway Network.

Syria and its neighboring Middle East countries have been engaged in constructive discussions, within the framework of "Director General Middle East organization" (DGMO), to connect their railway networks and to improve the rail transport services between these countries. DGMO consists of Syria, Iran, Turkey, Egypt, Iraq, Lebanon, Jordan and Saudi Arabia. Other Arab Gulf states, Central Asian countries, Pakistan, Afghanistan and India are not members yet, but in the future their railway networks will be linked to the DGMO members' railway networks after the development of DGMO' network.

It's important for Syria to develop its railway network in order to serve international railway transport along main regional routes. 
مجلة العلوم الهندسية - العدد السابع - ديسمبر 2014

مُسْنَخْلص:

تعتبر سوريا بلد ملائم للنقل بالسكك الحديدية من حيث موقعها الجغر افي اذ تتوضع نسبة كبيرة من السكان

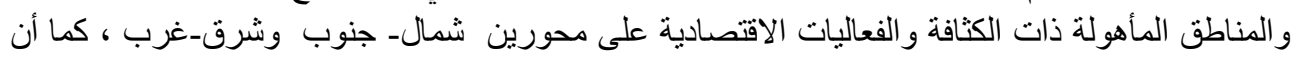
المسافات بين المدن الرئيسية ملائمة وكافية لتجعل السكانكات الحديدية منافساً قوياً في مجال خدمات نقال نقل الركاب

و البضائع.

تربط شبكة الخطوط الحديدية السورية بين:

• • مر اكز الانتاج و الاستهلاك (نقل محلي).

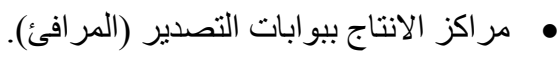

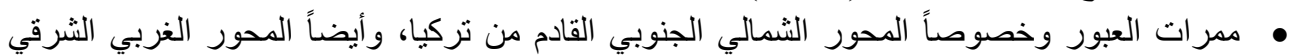

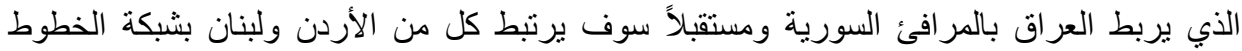

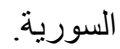

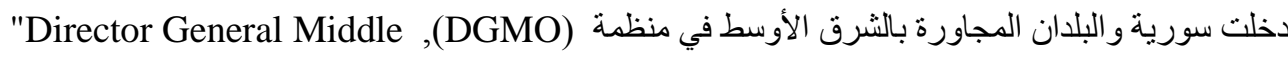
East Organization"

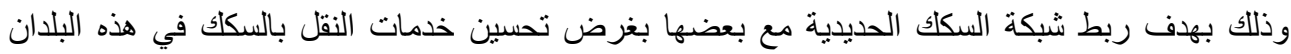

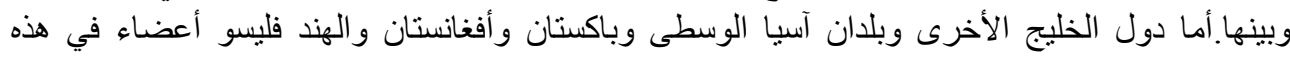

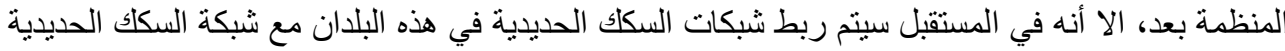
اللبلدان الأعضاء في منظمة (DGMO) بعد أن يصار الى تطوير شبكاتها بشكل مناسب.

و ون هنا فانه من المهم لسوريا أن تطور شبكتها بهذف خدمة النقل الدولي و العابر بالسكك الحديدية فيما يتعلق بالمحاور الرئيسية.

مقدمة:

تبدو أهية قطاع النقل جليّةً من خلال علاقته التي تتسم بالتأثير المتبادل مع القطاعات الاقتصادية

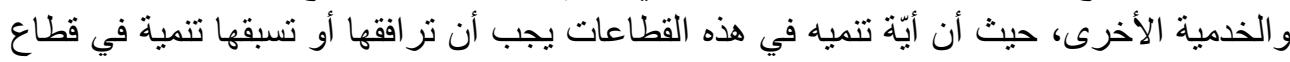

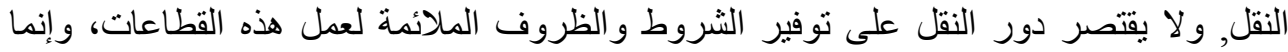

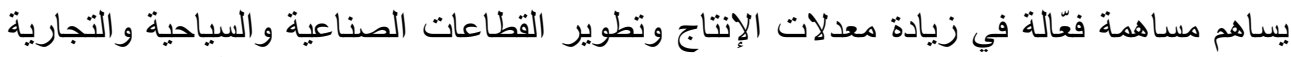

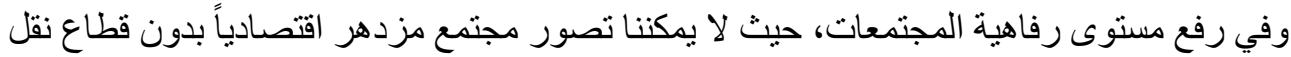

منطور.

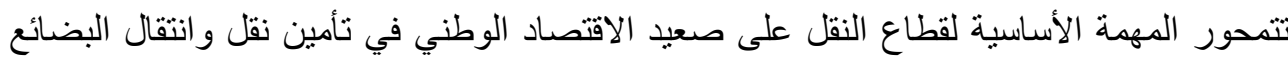

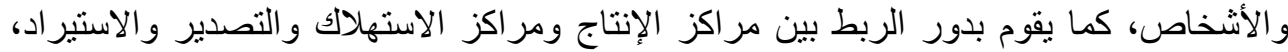

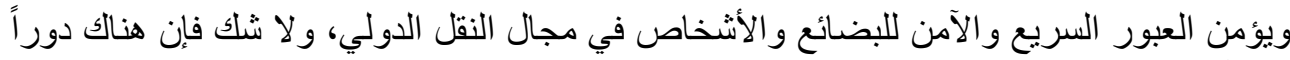

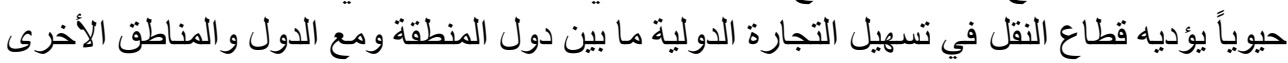
وخصوصاً في ظل الاتجاهات المتز ايدة نحو تحرير الخدمات

A -39 
وتعتبر شبكة النقل والمواصلات وخصوصا شبكة الخطوط الحديدية بحقِ الثريان الأساسي

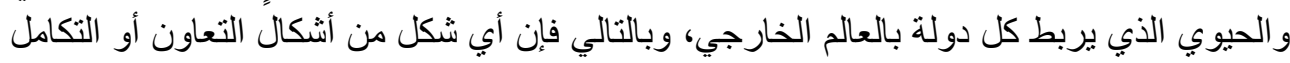

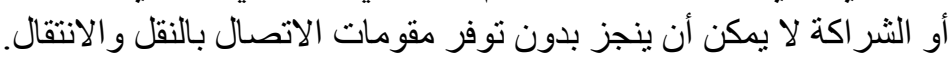

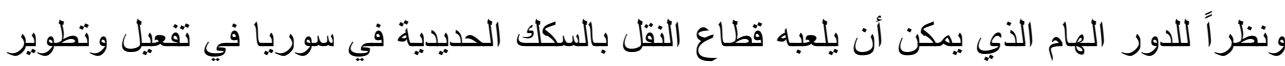

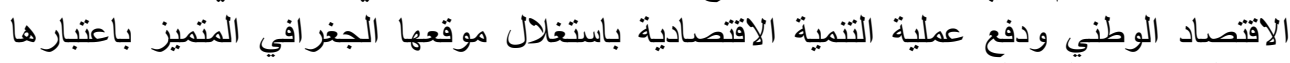

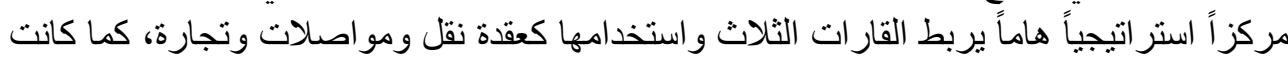

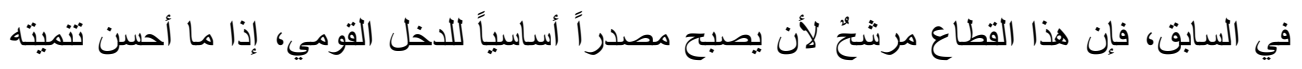
وتطويره و استثماره.

أولاً: خصائص النقل السكي: و ونمي:

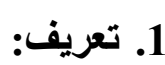

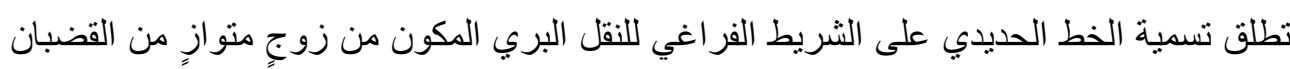

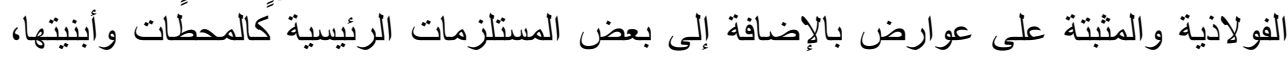
ونظم الإشار ات و الاتصالات وكنلك الأدو ات المحركة و المتحركة التي تسير عليها.

\section{2. مزايا السكك الحديدية:}

تحتل السكلك الحديدية مكانة رفيعة بين مختلف أنماط النقل، وتعتلي هذه الأهمية لامتلاكها العديد من الخصائص و المز ايا:

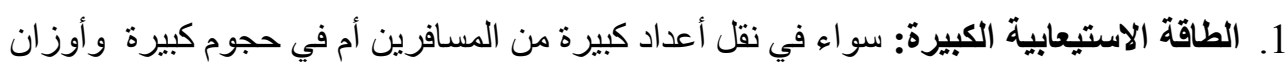

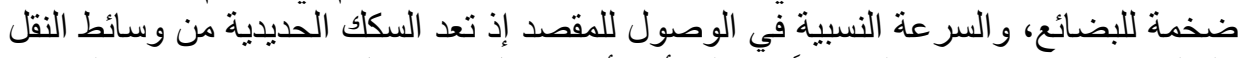

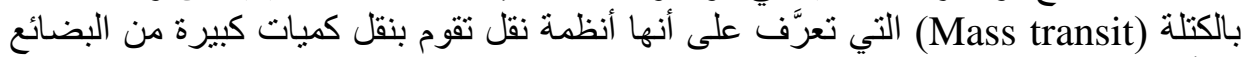
والأفر اد في وقت قصير مقارنة بغير ها من الوسائل.

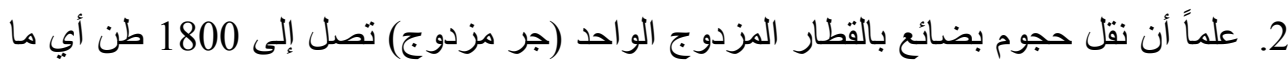
يعادل حمولة 50 سبارة شاحنة.

3. الآثار السياسية: تكمن الآثار السياسية للنقل بالسكك الحديدية بالحالتين التاليتين:

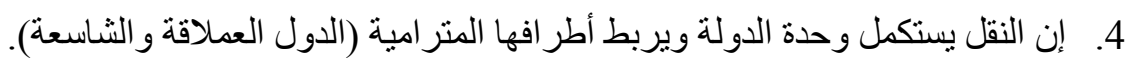

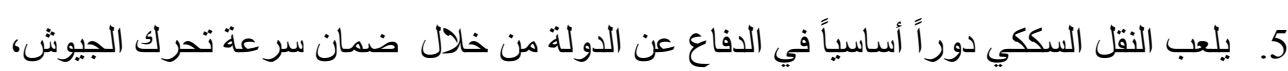
ونقل العتاد العسكري و اللوجستي.

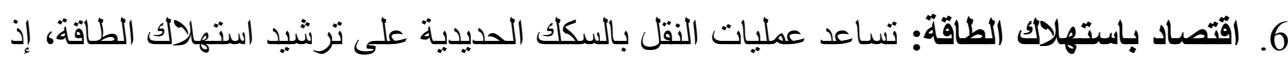

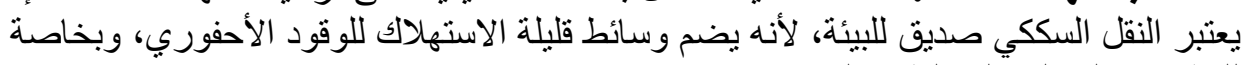
للقطار ات العاملة على الطاقة الكهربائية. 
مجلة العلوم الهندسية - العدد السابع - ديسمبر 2014

7.صديق للبيئة: إن قدرة القطار ات على توفير الطاقـة هي إحدى إسهاماتها الكامنة للبيئة والاقتصـاد

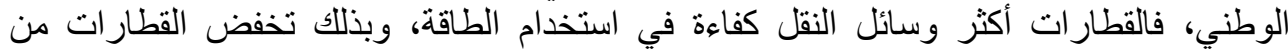
استهلآك الدول من النفط وبالتالي تقلل من انبعاث الغاز اتل النّات الملوثة.

8.متطلبات مكانية ضئيلة: للخطوط الحديدية القدرة على تحسين الاستخدام الأمثل للمساحات المحلية

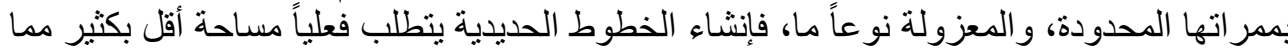
تنطلبه الطرق السريعة و المطار ات.

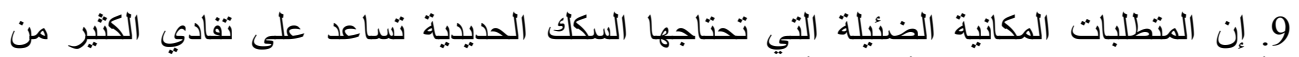

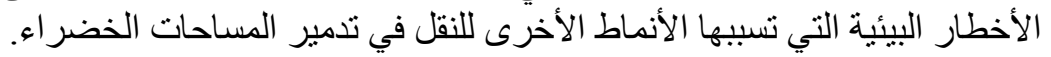

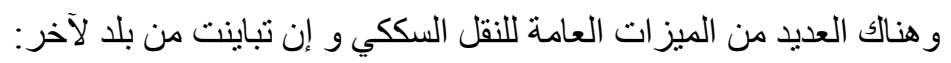
• النقل بالسكك الحديدية أقل تأثراً بالعو امل الجوية المختلفة. • التخفيضات على أجور النقل في السكك الحديدية وفق المسافات التي تقطعها الحمو لات تصل حتى 30\%. • الدقة في المو اعيد من حيث لحظة الانطلاق وزمن الرحلة وزمن الوصول. • إمكانية توفير مجموعة من الخدمات كالمنامة والمطاعم وذلك من خلال وجود عربات مخصصة لتقديم هذه الخدمات.

• أسعار النقل السككي معتدلة، ومنافسة لبقية وسائط النقل الأخرى، وهي أقل من أسعار النقل الجوي و البري ولكنها أعلى من النقل البحري.

3. المردود الاقتصادي للسكك الحديدية:

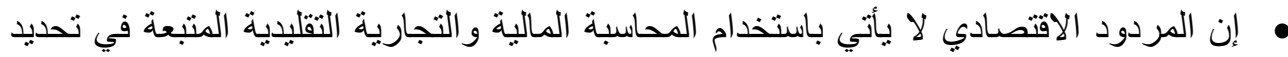

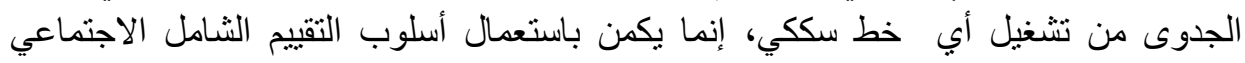
و الخدمي و البيئي و الاقتصادي و الذي لتي يتضمن: تكلفة الحوادث: حيث تؤمن السكك الحديدية دخلاً اجتماعياً ملموساً بتخفيض أعداد الوفيات

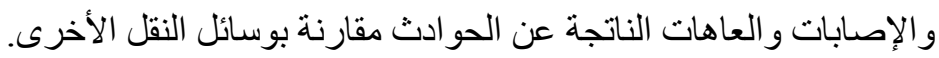
تلوث البيئة: لقد ازداد الاهتمام العالمي في الآونة الأخيرة بشؤون المحافظة على البيئة والإقلال

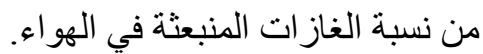

• اختناقات المرور: إن الاختناقات نادرة في النقل السككي بينما تكون الاختناقات الطرقية كثيرة

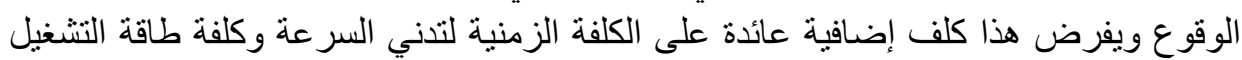
بمردود منخفض وكلفة التلوث العائد للازدحام وكلفة استعمال المركبات و البنية الأساسية. 


\section{4.مساوئ النقل بالسكك الحديدية}

هناك العديد من المساوئ لهذا النمط من النقل نذكر منها:

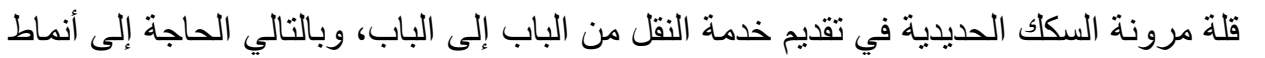

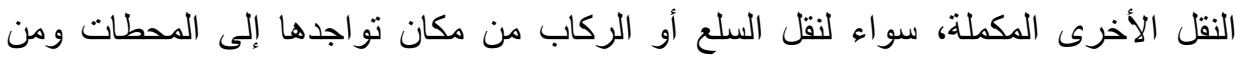

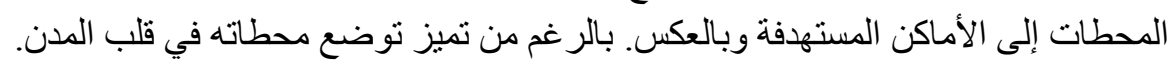

$$
\text { تكاليف إنشاء الخطوط و المحطات مرتفعة بالإضافة لارتفاع تكليف الصيانة. }
$$

خدمات النقل محدودة في الأماكن التي تتواجد فيها السكك الحديدية وقصور ها في تأمين خدمات

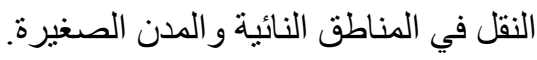

من أجل تقليل عيوب النقل بالسكك الحديدية لجأت مؤسسات النقل بالسكك الحديدية إلى وسائل متعددة

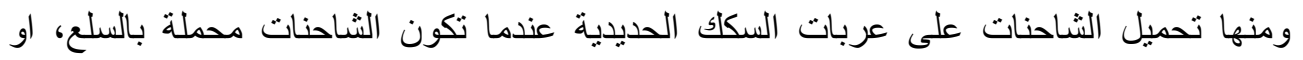

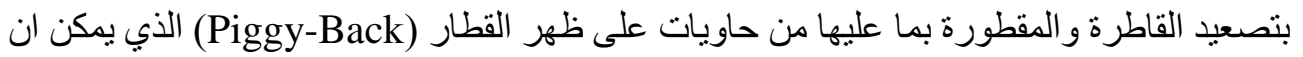

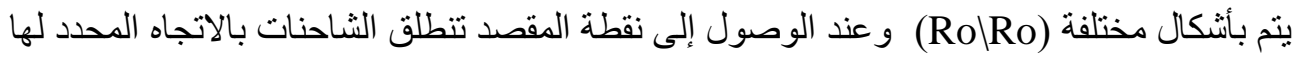

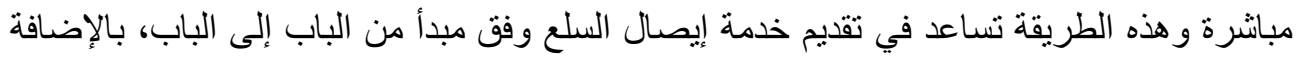

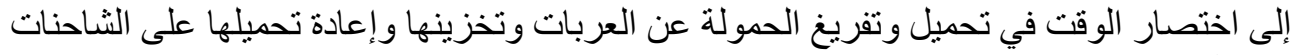

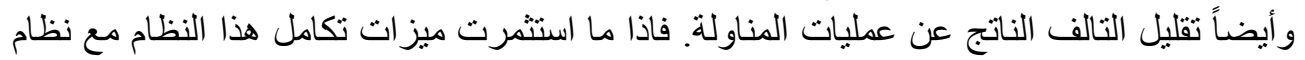

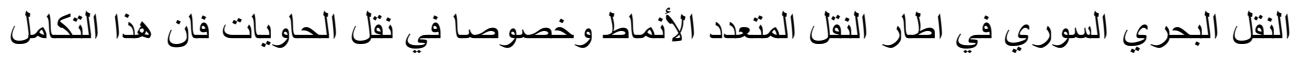
يشكل مصدر الهاما للاخل القومي السوري.

ثانياً: العناصر الأساسية للنقل بالسكك الحديدية

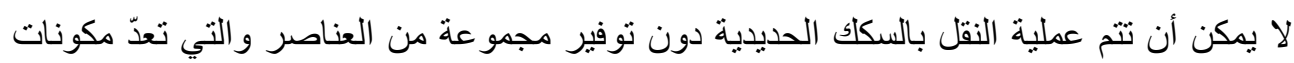
لأي نظام نقل سككي.

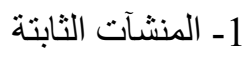

2 - و العناصر المحركة و المتحركة

3 - أنظمة الإشـار ات و الاتصالات.

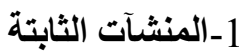

تتكون من:

•الخطوط الحديدية.. ومنها المنفردة والمزدوجة و المتعددة المحاور.

•الجسور و الكباري.. التي تقام على تقاطعات الطرق، وفوق المسطحات المائية الضيقة كالأنهار

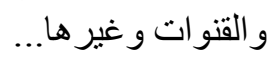


•المحطات.. وهي على نوعين: المحطات الرئيسية وتكون غالباً في المدن الكبرى، والمحطات

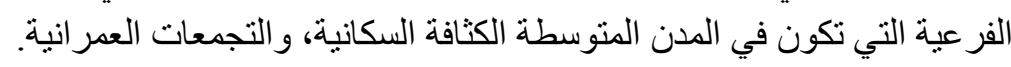
يعد القسم العلوي للخط الحديدي المعيار الأساسي الذي يحدد جودة الخطوط الحديدية إذ يتألف من

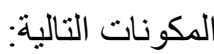

أـ القضبان: وهي العناصر المعدنية التي تقوم بوظيفة نوجيه العجلات وتوزيع الحمولات

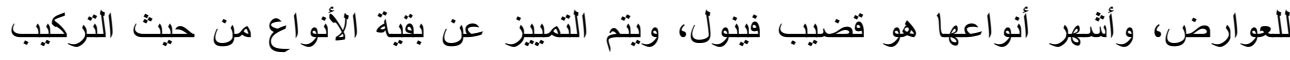

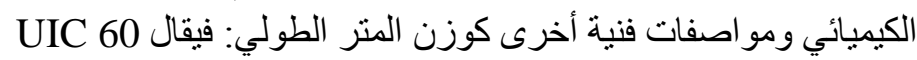

بـ العوارض: وهي عناصر تتوضع بشكل عرضي على مسار السكة تقوم بوظيفة حمل القضبان

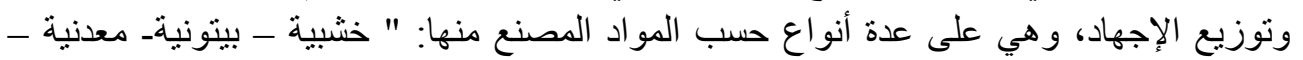

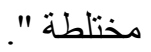

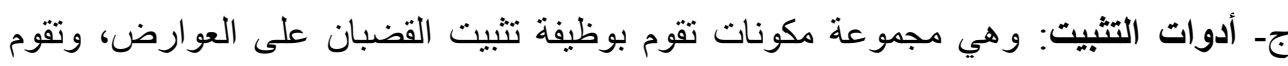

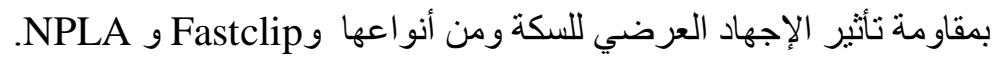

دـ طبقة البلاست: هي وسادة الرمل وموشور البحص الحاضنة للعوارض على سطحها العلوي تؤمن وسطاً مرناً لاستناد العوارض وضادة الرتوزيع الإجهادت إلى القسم السفلي للخط.

هـــ المفاتيح: وهي مجموعة من العناصر التي تقوم بتحويل مسار القطار ات من سكة لأخرى.

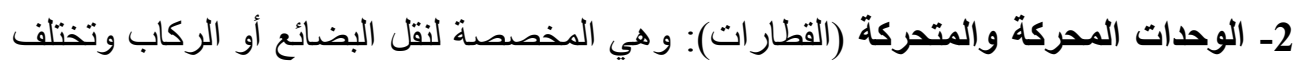

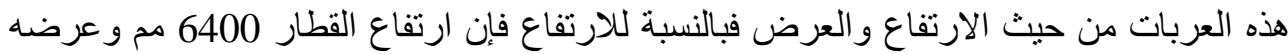

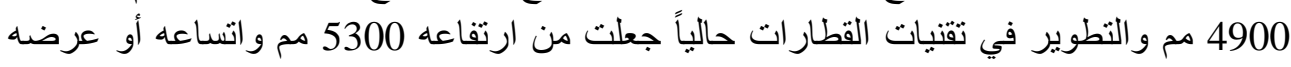
3600 مم... وتضم: •القاطرات، التي منها قاطر ات ذات قدرة كبيرة تعادل 2500 حصان ومافوق.. ومنها جرارات متوسطة القدرة تتر اوح قدرنها حول 1650 حصاناً.

$$
\text { •عربات الركاب. }
$$

•عربات ذات تجهيز خاص.. و هي أنواع كثيرة، منها: عربات النوم، وخز انات نقل النفط،و عربات

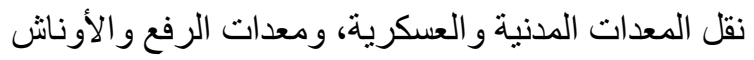
3- 3 أنظمة الإشارات والاتصالات - ويشتمل الإشار ات الكهربائية، و الإشار التشات الميكانيكية: وتكمن أهمية هذه الأنظمة بأنها أحد الركائز الأساسية في تنظيم مسير القطار ات و تحقيق الآمان و السلامة. 


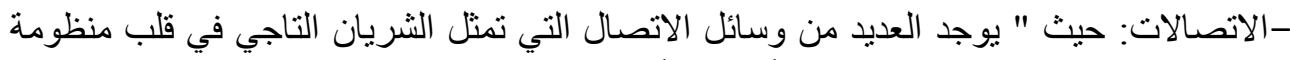

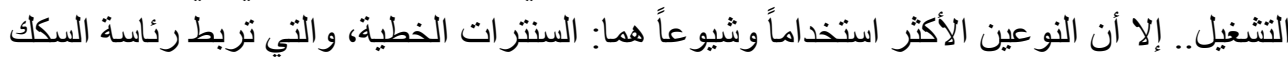

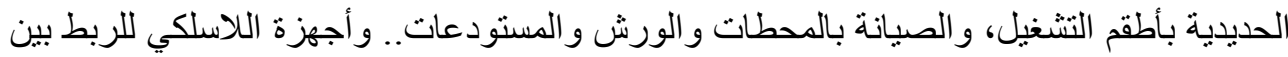

وحدات و عناصر تشغيل وتأمين الوحدات المتحركة".

•نظم التحرك: وهي المعنية بتنظيم " حركة ومسير القطارات، سواء للمرور أو للقدرات أو لعو امل الأمان. وتستخدم هذه النظم الوسائل السلكية و اللاسلكية.

ثالثاً: الواقع الحالي للخطوط الحديدية السورية:

1 1 1ميزات النقل السككي في سوريا:

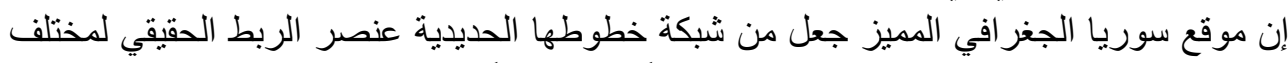

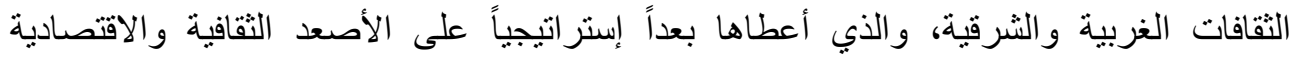

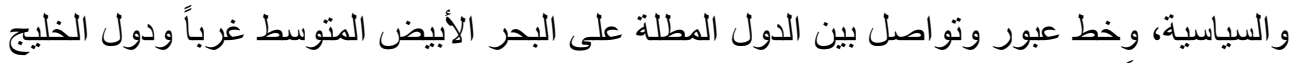
العربي شرقاً.

بما أن النقل يعتبر المتأثر والمؤثر الأول في الموقع الجغرافي حيث يؤمن الربط والتبادل الثقافي

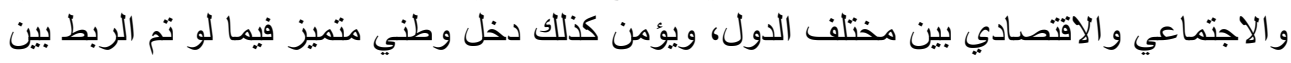

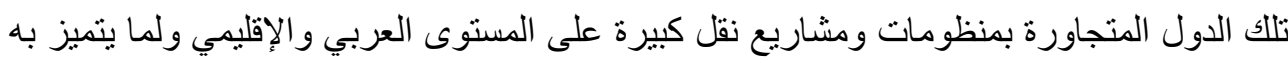
النقل السككي يمكن أن يكون له دور أساسي و هام في هذه المشاريع التشاريع. ويمكن حصر ميز ات الثبكة السككية الوطنية بما يلي:

- تغطي الشبكة السورية لكامل مر اكز المحافظات و المدن الصناعية و المر افئ وترتبط بالثبكتين التركية و العر اقية.

- إمكانية النقل من المرافئ السورية إلى المرافئ الجافة والداخل حيث مراكز الإنتاج والمدن الصناعية و المناطق الحرة.

-تلبي الحاجة للنقل من المر افئ السورية باتجاه دول الجوار ومر افئها وبخاصة العراق. -جدوى النقل بالسكك الحديدية محلياً، ومنافسته الكبيرة للنقل البري من حيث طول المسافات

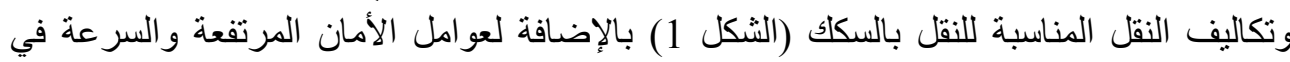
الوصول للمقصد. 


\section{تكامل أنماط النقل}

\section{مقارنة كلف النقل بين السكك و الطرق}

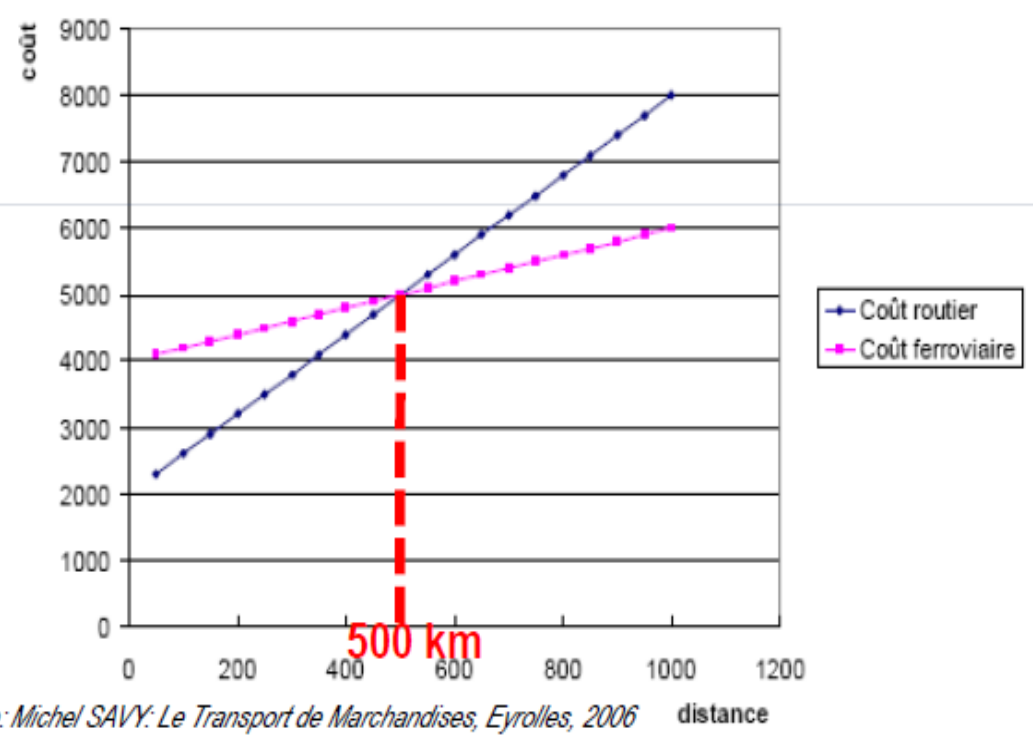

Source: Miche/ SAVY: Le Transport de Marchandises, Eyrolles, 2006 distance

الثكل (1): النقل بالسكك يصبح أكثر جدوى من النقل بالثاحنات لمسافات أكبر من

.5500

ترتبط المحافظات والمدن السورية بشبكة خطوط حديدية رئبسية نظامية بعرض 1435 مم بلغ طولها حتى نهاية عام 2009م 2495كم منها (1801) كم خطوط رئبسية، ملحقة بشبكة تفريعات بطــول (318) كم، فضلا عن المحطات بطول (376) كم، حيث يتم نقل كل من الركاب و البضائع بوساطة عربات وشاحنات تجرها قاطرات مختلفة،و بقوة جر تصل حتى 3200 حصان، وقد احتفلت المؤسسة العامة للخطوط الحديدية السورية عام 2003 بمرور مائة عام على إنشاء أول خط حديدي في الأراضي السورية حيث نم إنشاء أول خط حديدي في سورية هو خط حلب - ميدان اكبس الحدود التركية في عام 1903م. 


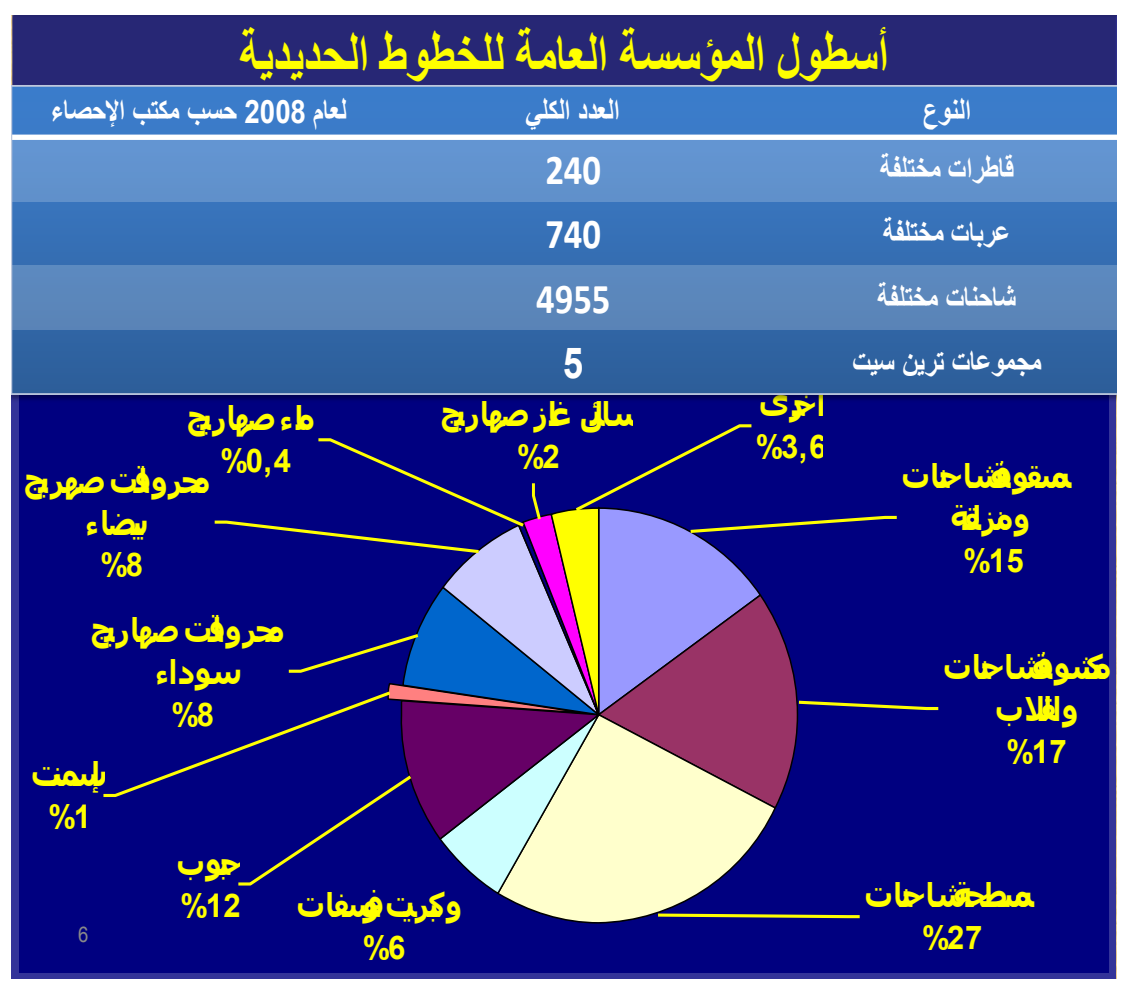

الثكل (2): يبين موجز لأسطول النقل في المؤسسة العامة للخطوط الحديدية السورية

(المصدر المجموعة الإحصائية)

وقد اعتمدت المؤسسة العامة للخطوط الحديدية السورية برنامجا للنطوير والتحديث عام 2000 تضمن تمديد 37 كم خطوطاً جديدة بشكل سنوي، وتجديد خطوطا قديمة بمتوسط 10 كم سنويا،

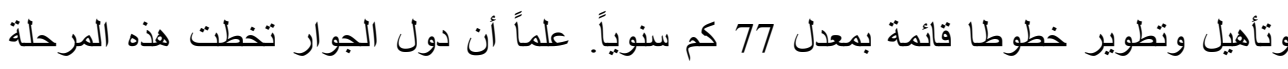
بأثو اط حيث ينت في تركيا إنشاء خطوط جديدة بمعدل 600 كم طولي سنويا من الخطوط الحديدية، كما تقوم بتأهيل وتطوير 450 كم سنويا من خطوطها , وفي إيران ينم إنشاء خطوط جديدة وتجدد بعض خطوطها بمعدل500 كم سنويا، كما تقوم بتأهيل وتطوير 350 كم من خطوطها الحديدية. و الجدول التالي يبين أطو ال الخطوط الحديدية السورية بالتفصيل: 
مجلة العلوم الهندسية ـ العدد السابع - ديسمبر 2014

الجدول(1): مقاطع الخطوط الحديدية بالتفصيل وأطو الها

(المصدر المجموعة الإحصائية 2010 ) (1) معطية

\begin{tabular}{|c|c|c|c|c|}
\hline \multirow{2}{*}{ Name of Line } & \multicolumn{3}{|c|}{ 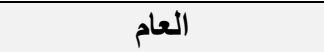 } & \multirow{2}{*}{ 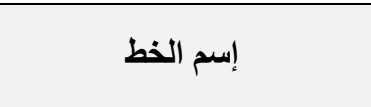 } \\
\hline & 2009 & 2008 & 2004 & \\
\hline Ordinary Line & 2495 & 2495 & 2495 & خط عريض(المجموع) \\
\hline Lattakia.Al-Kamishli & 1044 & 1044 & 1041 & اللاذقية، حلب، القامشلي \\
\hline Al-Kamishli-Al- Yarubieh & 90 & 90 & 90 & القامشلي، اليعربية \\
\hline Aleppo.Hama.Homs & 304 & 304 & 303 & حلب، حماه، حمص \\
\hline Akkari.Homs.Damas & 407 & 407 & 407 & عكاري، حمص، دمشق \\
\hline Alleppo.MidanEkbes.Rae & 190 & 190 & 190 & حلب، ميدان أكبس، الر اعي \\
\hline Homs.Kseyr & 45 & 45 & 45 & حصص، القصير \\
\hline Akkare.LibaneseBandaries & 5 & 5 & 5 & عكاري، الحدود اللبنانية \\
\hline Mahin.Phosphatemines & 154 & 154 & 154 & مهين، مناجم الفوسفات \\
\hline Tartous.Akkari & 92 & 92 & 92 & طرطوس، عكاري \\
\hline Tartous.Lattakia & 134 & 134 & 134 & طرطوس، اللاذقية \\
\hline Deir.ez.zor..AlTabia & 30 & 30 & 30 & دير الزور، الطابية \\
\hline Narrow Line & 338 & 338 & 338 & خطازيقلازلخط الحلديدي \\
\hline Damascus.Dara & 127 & 127 & 127 & دمشق، درعا \\
\hline Dara.Nasseb & 13 & 13 & 13 & در عا، نصيب \\
\hline KummGarz.Busra & 34 & 34 & 34 & قم غرز، بصرى \\
\hline Dara.Al.shajara & 42 & 42 & 42 & درعا، الثجرة \\
\hline Al.Shajara.Al.Himmeh & 24 & 24 & 24 & الثجرة، الحمة \\
\hline Sergaya.Damascus & 58 & 58 & 58 & سر غايا، دمشق \\
\hline Al.kadam.Qatana & 33 & 33 & 33 & القدم، قطنا \\
\hline Sergaya.lebaneseboraer & 7 & 7 & 7 & سر غايا، الحدود اللبنانية \\
\hline TOTAL & 2833 & 2833 & 2799 & المجموع(الضيق والعريض) \\
\hline
\end{tabular}




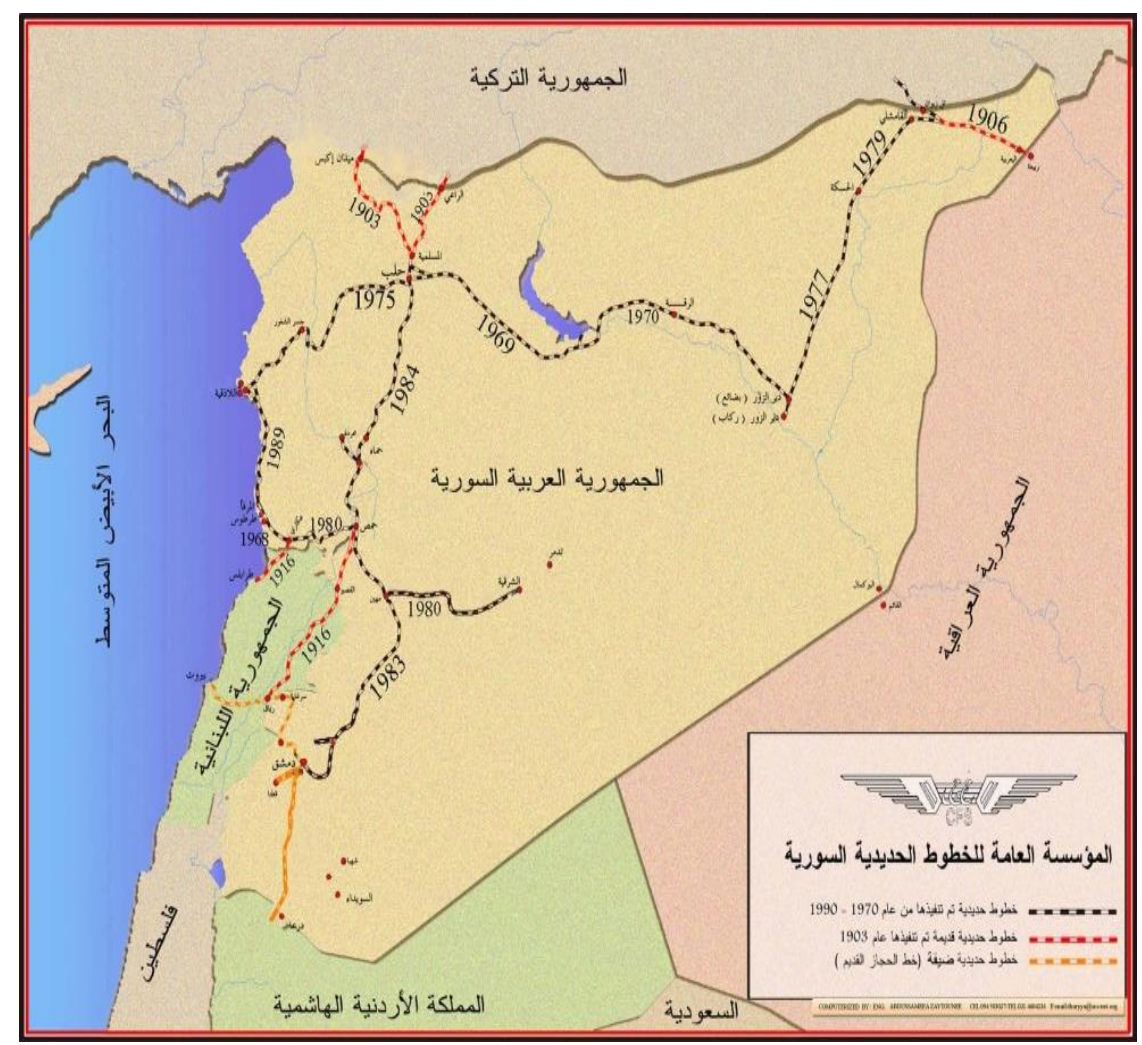

\section{الثكل (3): التطور التاريخي لثبكة الخطوط الحديدية السورية}

يبين الثكل (3) التطور التاريخي الكبير في نقل الركاب والبضائع عبر شبكة الخطوط الحديدية سو اء للركاب أو للبضائع:

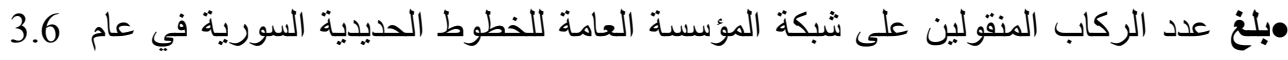

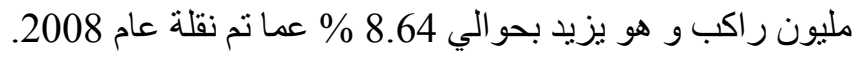
•كما بلغت كمية البضائع المنقولة 8.842 مليون طن و يقل بحوالي 5 \% \% عما تحقق بالعام 2008 و البالغ 9.307 مليون طن. 
مجلة العلوم الهندسية - العدد السابع - ديسمبر 2014

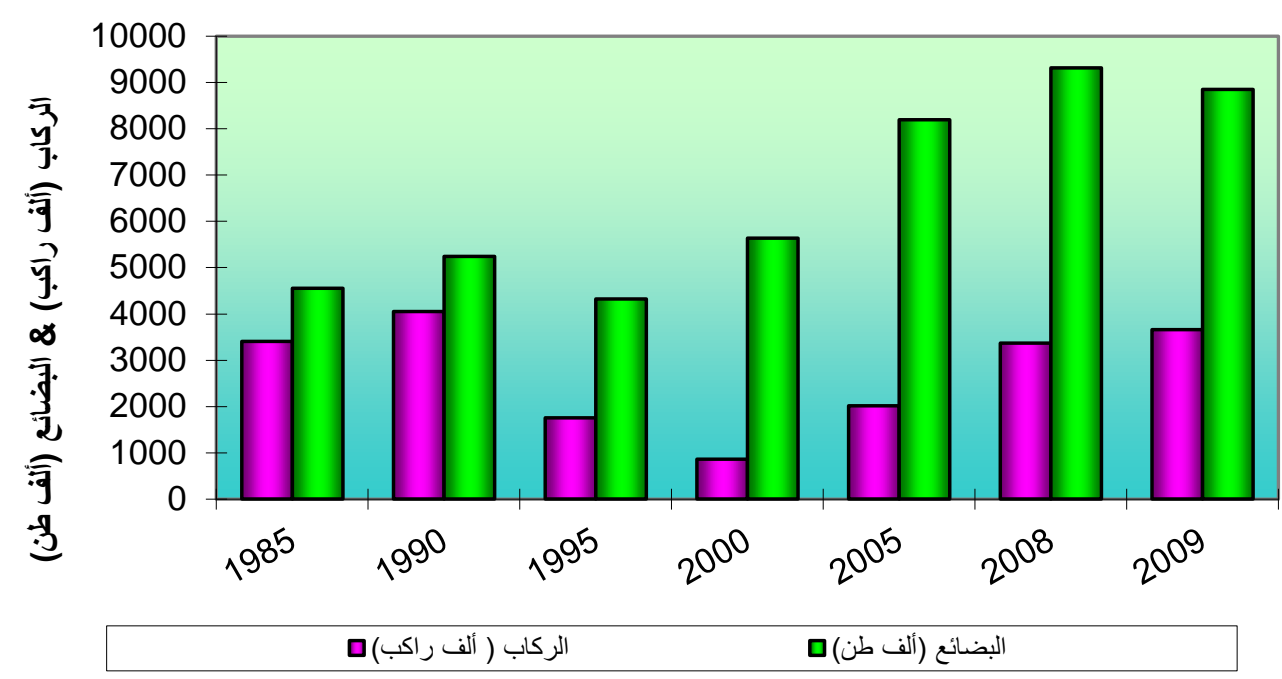

الثكل رقم (4): تطور حجوم النقل السككي (للركاب والبضائع) في سورية (1985 -2009)

\section{رابعاً: أهمية شبكة الخطوط الحديدية السورية عربياً وعالمياً:}

يعتبر القطر العربي السوري بحكم موقعه الجغر افي بوابة الاتصال مع الثبكات الحديدية الأوروبية

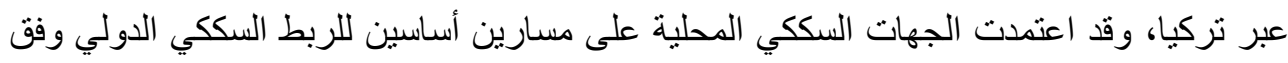

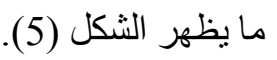
•المسار الأول غرب ـ شرق من المر افئ السورية (مرفأ طرطوس) الى الحدود العر اقية ـالسورية. •المسار الثاني شمال - جنوب من الحدود السورية التركية شمالاً الى الحدود السورية الأردنية جنوباً.

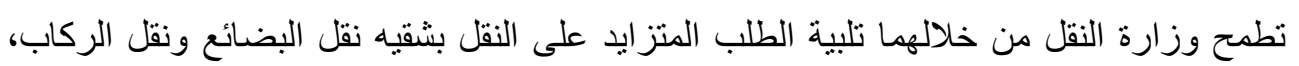
و إلى ربط سككي مع دول الجو ار وفتح الأبو اب للنقل العابر و استغلال المل الموقع الجغر افي المتميز. 


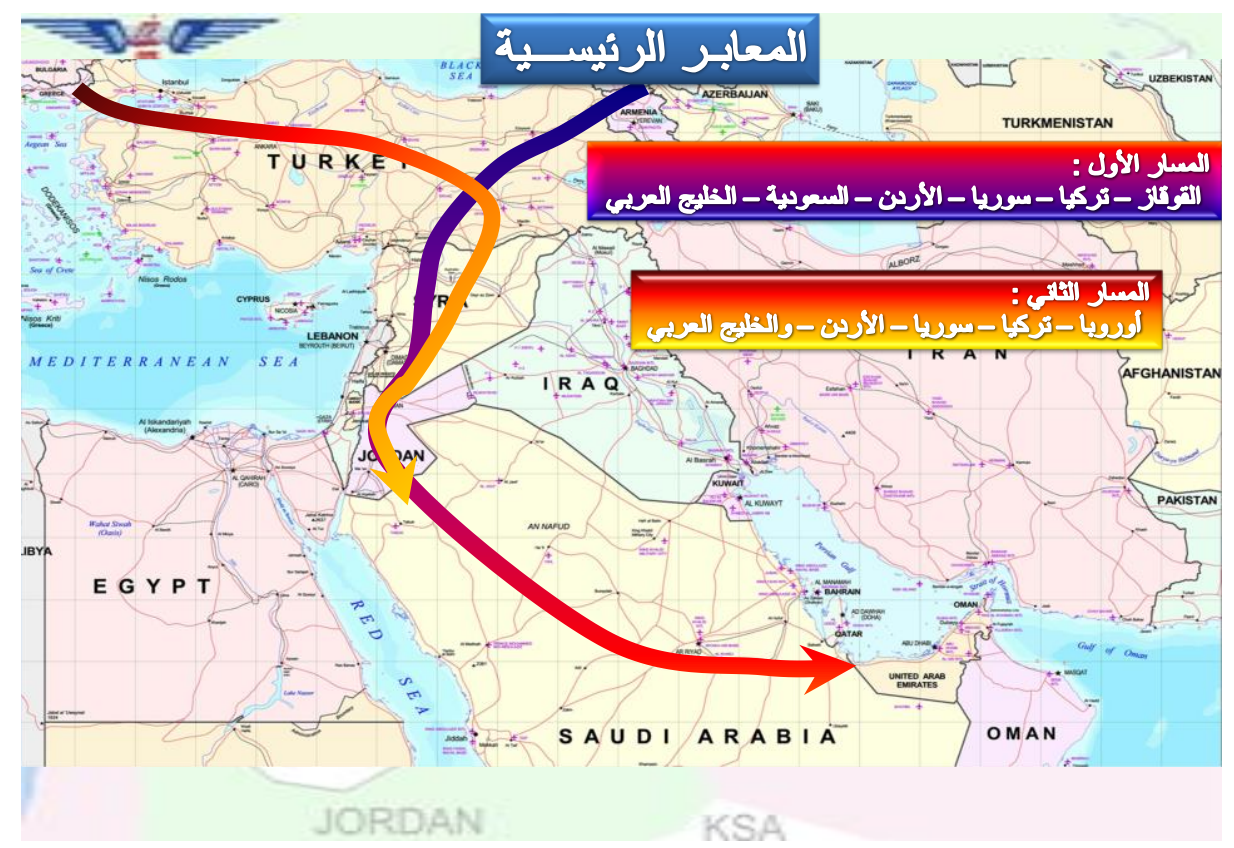

الشكل (5): مسارات الربط الدولي بالخطوط الحديدية السورية

إن إنجاز الربط السككي الجاري تتفيذه مع كل من العر اق والأردن، والاتفاق مع اليونان لتسيير خط الرارا السككي بين مرفأي اللاذقية وفولوس، بذلك تستكمل سوريا محاور الربط بشكل متكامل ومحكم مع الأقطار العربية والإقليمية والأوروبية.

ويظهر الثكل رقم (6) التالي محاور النقل بالخطوط الحديدية لثبكات الثرق الاوسط ودول آسيا الوسطى حيث يقدر نصيب سوريا من الحاويات ب (5) ملايين حاوية. 
مجلة العلوم الهندسية ـ العدد السابع - ديسمبر 2014

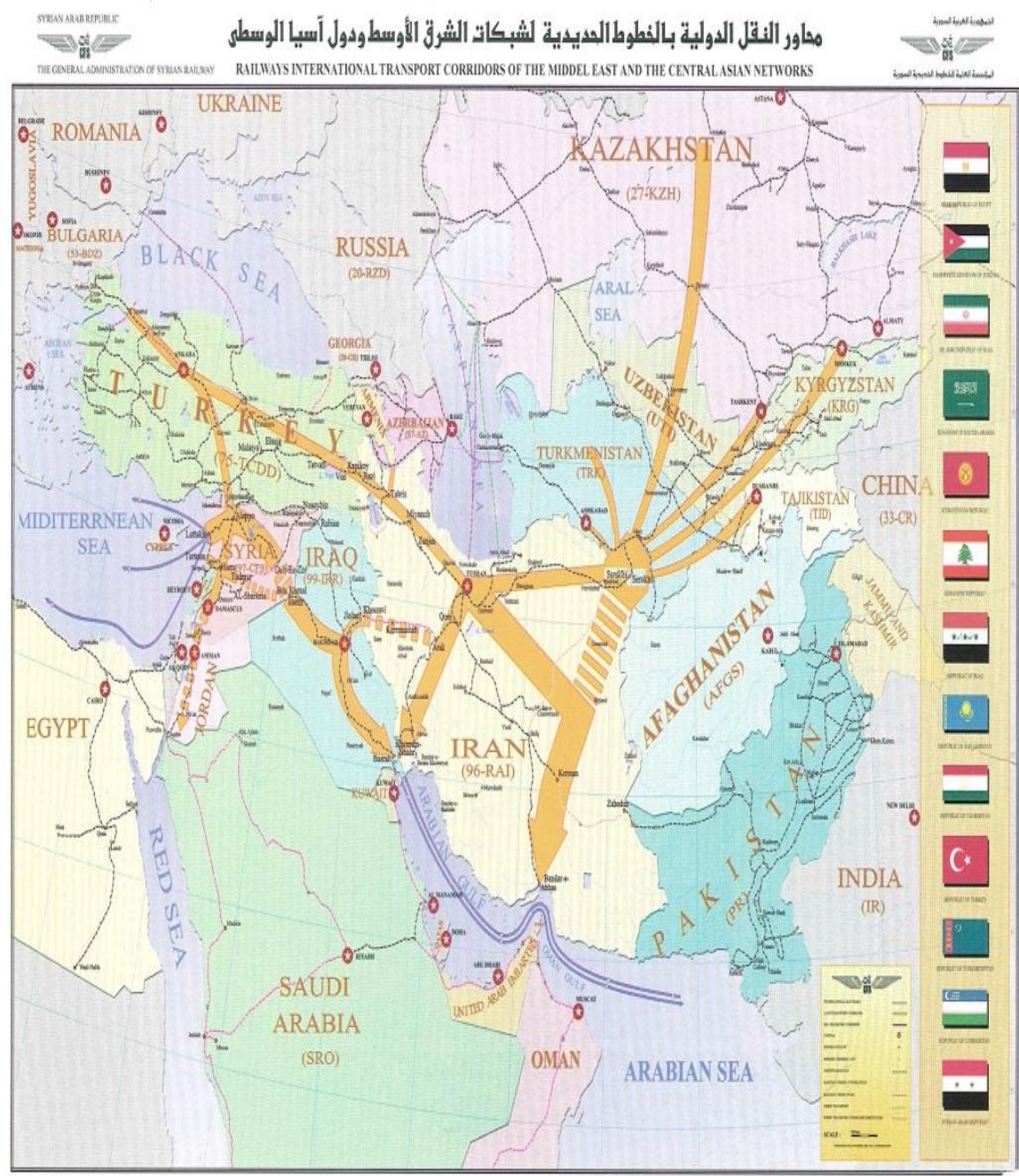

الشكل رقم (6): التالي محاور النقل بالخطوط الحديدية لشبكات الشرق الاوسط ودول آسيا الوسطى 
كما بين جدول المقارنة التالي بيانات ومؤشرات النقل السككي المجمعة من إحصاءات الاتحاد الدولي للسكك الحديدية UIC لبعض الدول العربية والعالمية، مكانة شبكة الخطوط الحديدية السورية بين

$$
\text { نظير اتها العربية و العالمية. }
$$

الجدول (2): مؤشرات النقل بالسكك الحديدية لعدة دول عربية وعالمية

(المصدر نشرات الاتحاد الدولي للسكتك الحديدية (UIC)

\begin{tabular}{|c|c|c|c|c|c|c|}
\hline \multicolumn{7}{|c|}{ بيانات ومؤشرات النقل بالسكك لعام 2007 لبعض الدول العربية و العالمية } \\
\hline الإيرانية & التركية & الروسية & اليابانية & الألمانية & الفرنسية & المؤشر \\
\hline 71.2 & 74 & 141.7 & 127.7 & 82.3 & 61.7 & عدد السكان مليون \\
\hline 1684 & 784 & 17093 & 378 & 357 & 552 & المساحة ألف ـ كم² \\
\hline 7265 & 8697 & 84158 & 20,050 & 33,897 & 60276 & طول الخطوط كم \\
\hline 5.17 & 11.09 & 4.92 & 53.04 & 94.95 & 109.20 & كثافة الثبكة ــ كم/ألف كم² \\
\hline 21 & 81 & 1280 & 8907 & 1835 & 1097 & عدد الركاب ـ مليون \\
\hline 20.5 & 9.68 & 2.090 .337 & 23.145 & 91 & 42.4 & مليون - طن.كم \\
\hline 12.549 & 5.5 & 173.411 & 252.579 & 74.74 & 83.299 & مليون ر اكب ـ كم \\
\hline 0.29 & 1.09 & 9.03 & 69.7 & 22.30 & 17.78 & عدد السكان ركاب السكك من \\
\hline الجزائر & الاردن & 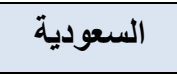 & 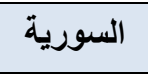 & 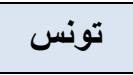 & 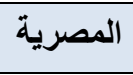 & 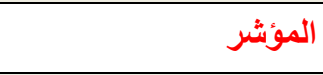 \\
\hline 33 & 6 & 25 & 19.9 & 10 & 73.4 & عدد السكان مليون \\
\hline 2381.74 & 90 & 2250 & 185 & 163.61 & 1001.4 & المساحة ألف ـ كم22 \\
\hline 4785 & 318 & 1412 & 2833 & 2506 & 9560 & طول الخطوط كم \\
\hline 2.01 & 3.53 & 0.63 & 15.31 & 15.3 & 9.55 & كثافة الثبكة ـ كم/ألف كم² \\
\hline 21.388 & & 1.071 & 2.492 & 38.8 & 451 & عدد الركاب ـ مليون \\
\hline 1.42 & 0.51 & 1.63 & 2.55 & 2.19 & 1.51 & مليون - طن.كم \\
\hline 0.91 & & 0.343 & 0.744 & 1.48 & 40.837 & مليون ر اكب ـ كم \\
\hline 0.65 & 0.00 & 0.04 & 0.13 & 3.88 & 6.14 & ندبة السكان ركاب السكك من \\
\hline
\end{tabular}


إن المساحة الكلية للوطن العربي تبلغ حوالي 14 مليون كم² ، أي تفوق على مساحسة أوربا 10

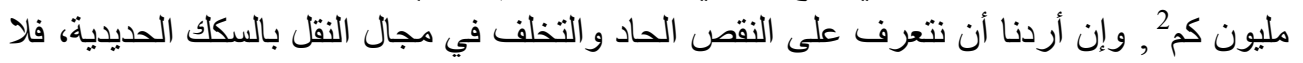

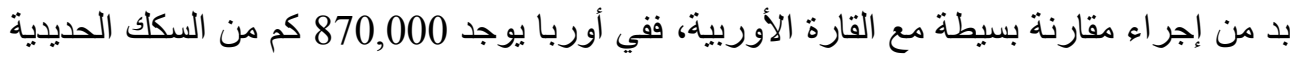
بينما لا يوجد سوى 25,561 كم في الوطن العربي، وهذاه الرنة الرقم لا يزيد عن ثلث الثبكة السككية الفرنسية.

من خلال المقارنة السريعة لتلك المؤشرات الموضحة في الجدول/ 2 / نتبين موقعنا السككي ضمن

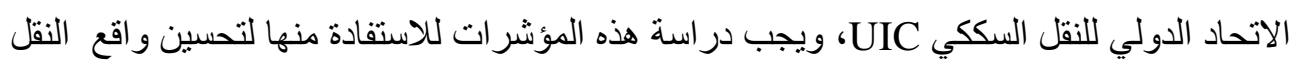
السككي ضمن منظومة النقل العام لدينا، وضرورة رفعه وتحسينه لما فيه من عائد هام على كافة

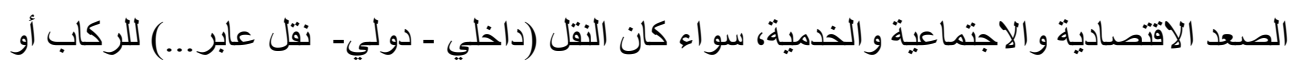

\section{طول الخطوط كم/المساحة 1000 كم2}

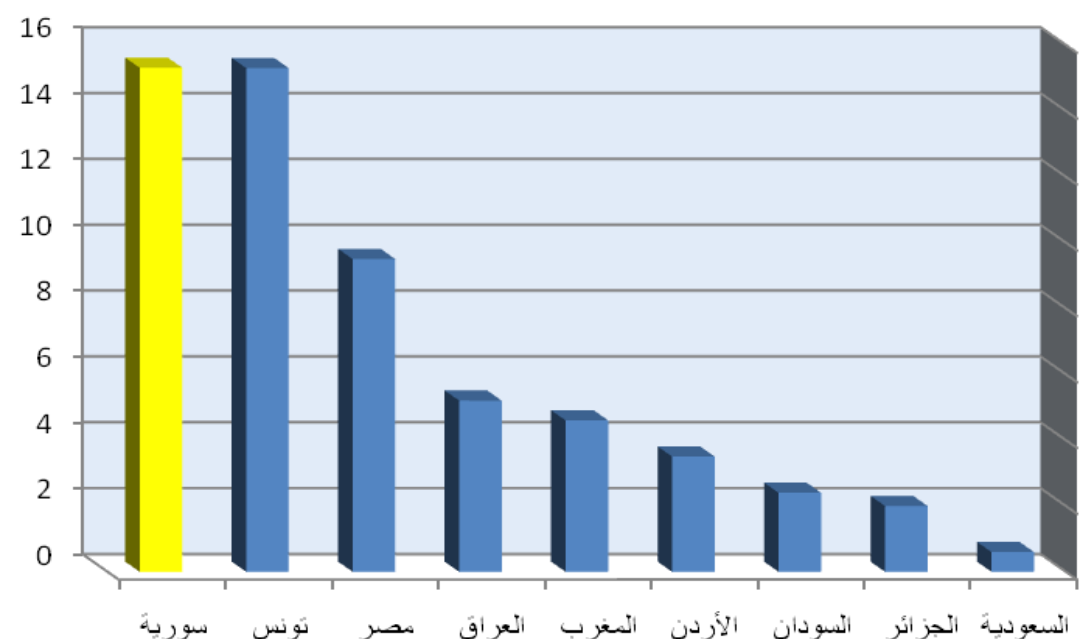

الثكل (7): مقارنة كثافة الثبكة السككية (طول الثبكة كم لكل 1000 كم2) عربياً

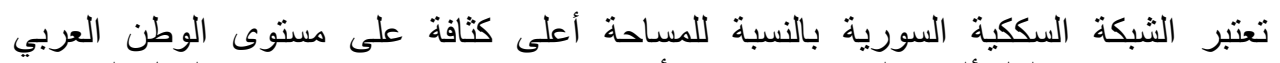

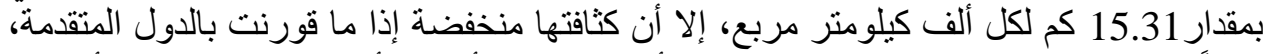

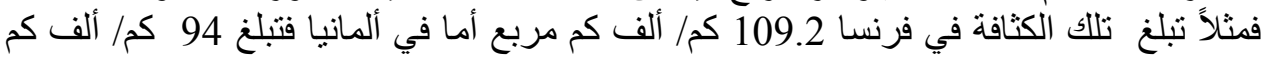
مربع. 
أما عامل استخدام الثبكة (غزارة النقل):

- بالنسبة لنقل الركاب فهو منخفض جداً في النقل السككي السوري مقارنة بدول الجوار و الدول

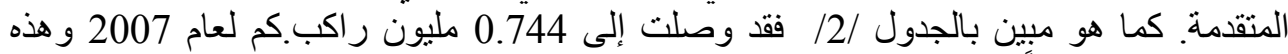

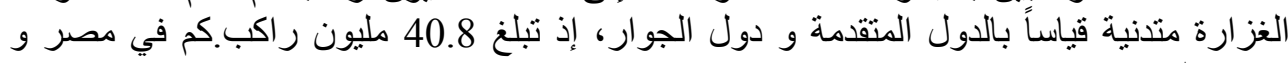

83.3

- أما غزارة نقل البضائع على الثبكة السورية فقد بلغت 2.55 مليون طن. كم و هذه الغز ارة مرتفعة التبا

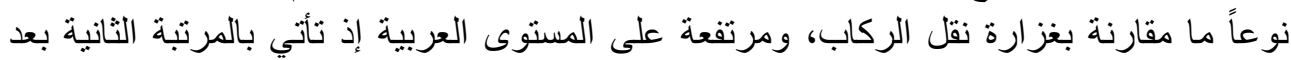

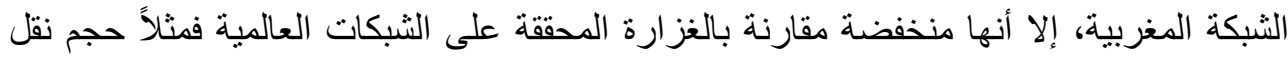

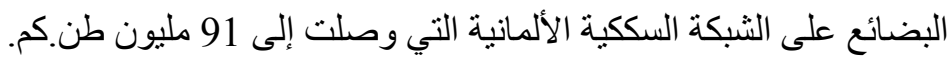

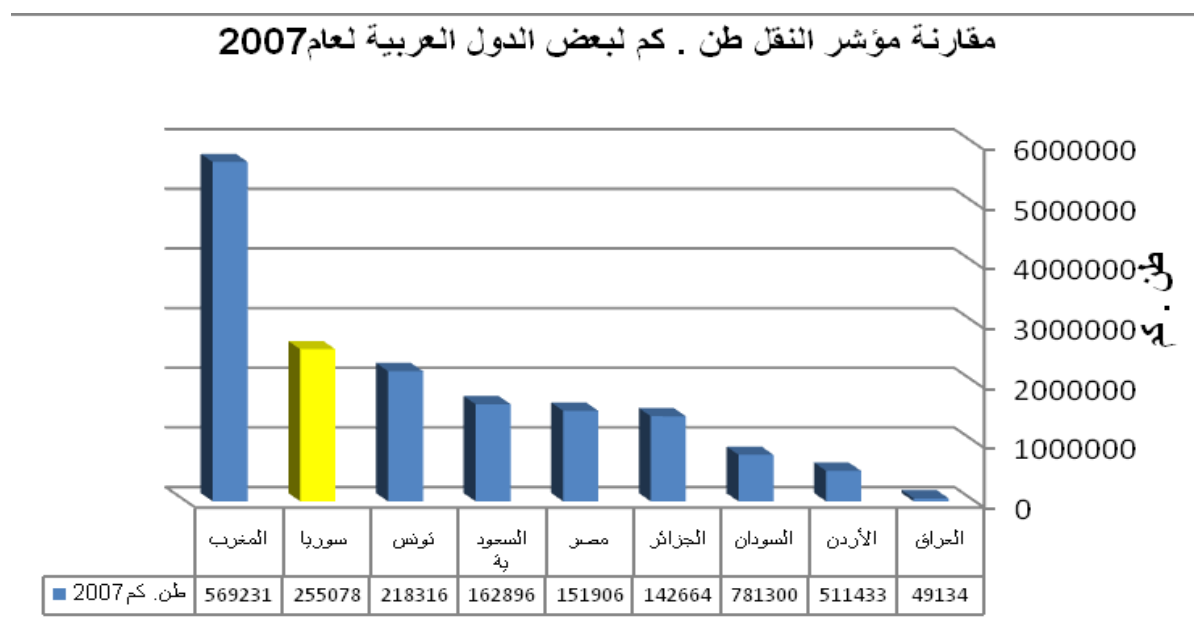

\section{الثكل (8): مقارنة مؤشر النقل ألف طن.كم لبعض الدول العربية}

من المخططات السابقة يتبين لنا الفرق الكبير في أطو ال الخطوط الحديدية ما بين دول أورباو دول المنطقة كذللك نسبة عدد الركاب من عدد السكان. وهذا يعكس اعتماد الدول المتقدمة الكبير على

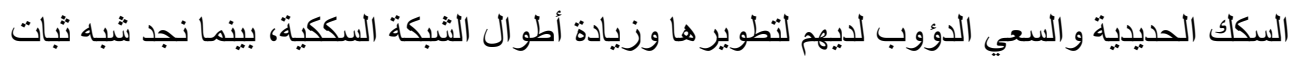
لأطوال الخطوط الحديدية عربياً، و في المنطقة بشكل عام وضعف النمو والاعتماد على النقل السككي و إدر الك لأهميته. - ميت. 
ومن خلال ماسبق وما تم الاطلاع عليه من مؤشر ات وبيانات وبدر اسة مقارنة يمكن القول:

1. إن انخفاض مستوى الأداء في شبكة الخطوط الحديدية السورية مرتبط إلى حد كبير بأعمال

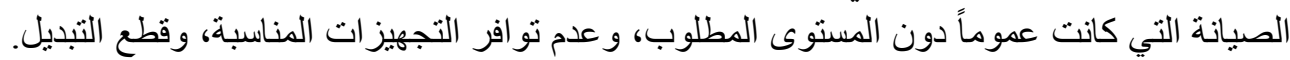

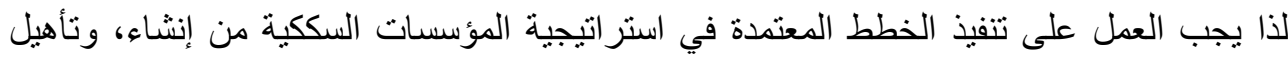

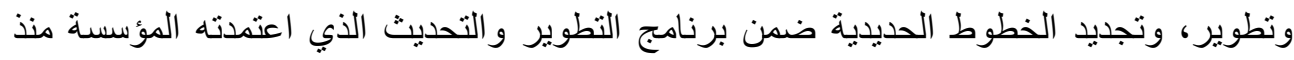

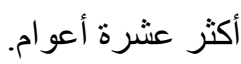

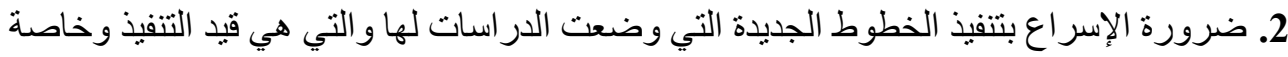

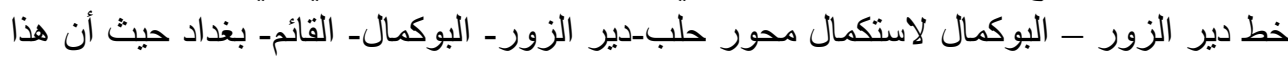

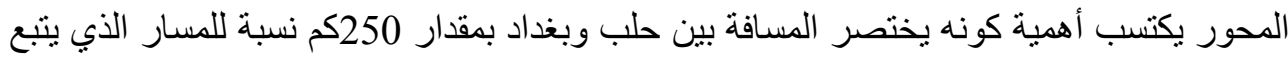

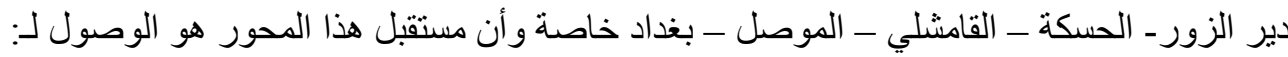

$$
\text { بغداد - البصرة - الكويت. }
$$

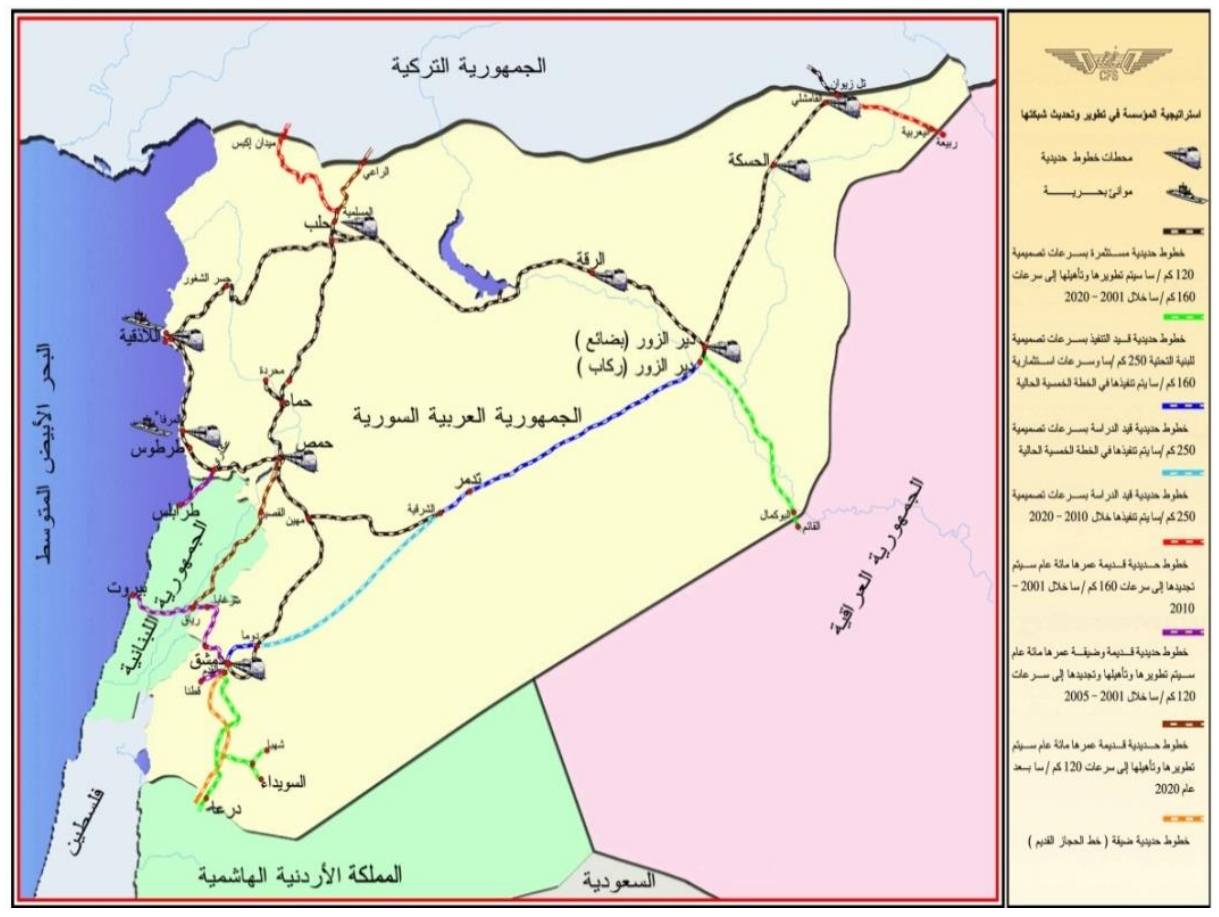

الثكل (9): خارطة شبكة الخطوط الحديدية السورية المقترحة حتى عام 2020 
3. المحافظة على جاهزية الأدوات المحركة و المتحركة وخاصة الثاحنات و القاطر ات كونها حالياً وللمدى المنظور تشكل العصب الحيوي و الأساسي لإير ادات المؤسسة المتأتية من نقل البضائع.

4. إحداث هيئة مختصة بدر اسة سوق النقل بشقيه نقل الركاب ونقل البضائع بدقة أكبر ليتسنى وضع الئع

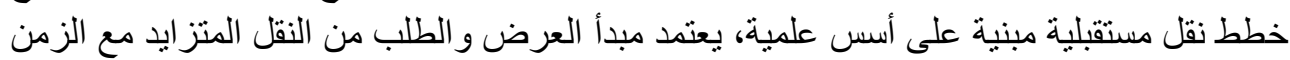

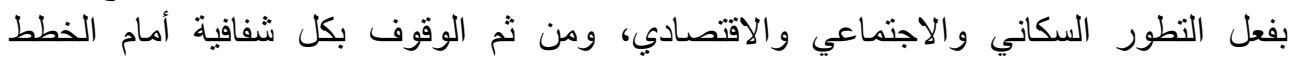

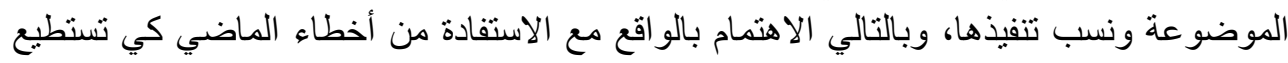

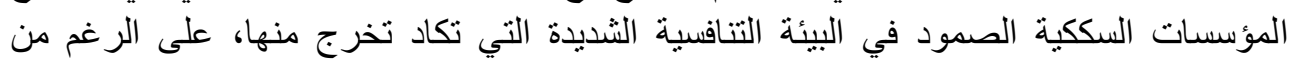
امتلاكها لكل مقومات المنافسة.

خامساً: خاتمة وتوصيات:

إن كفاءة النقل بالسكك الحديدية تتوقف على عدة عو امل، وهذه العو امل قد تكون ذاتية تتعلق بنظام النقل بالسكك الحديدية نفسه، أو عو امل خارجية تتعلق بالمواطنين ور غبتهم بالسفر بالسكك الحديدية،

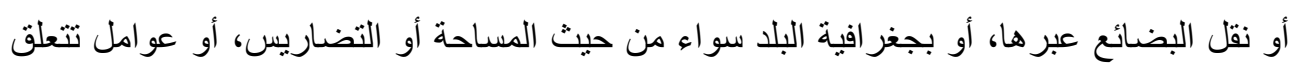

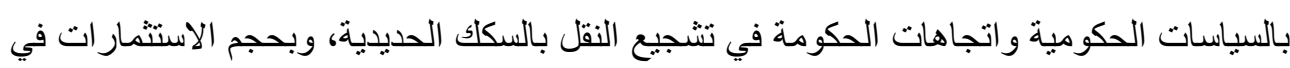

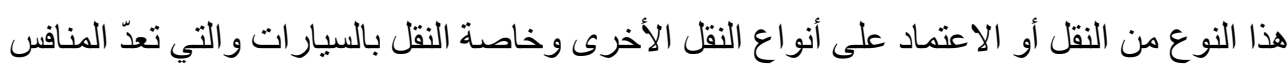

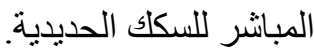

$$
\text { ويمكن تلخيص أهم الاقتر احات و استناتاجات الدر اسة بما يلي: }
$$

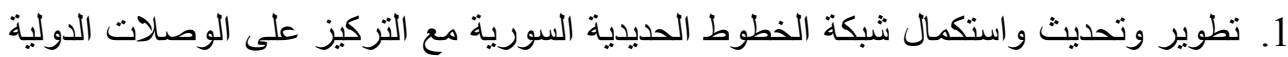

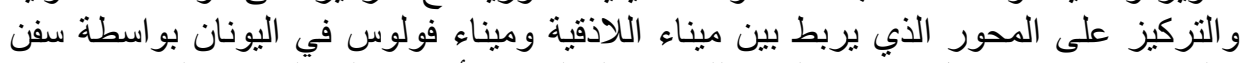

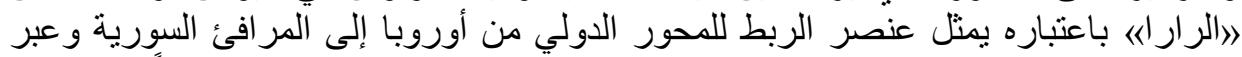

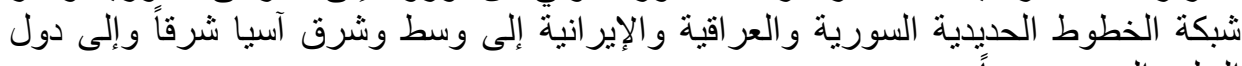
الخليج العربي جنوباً. 2. تفعيل دور النقل السككي السوري في النقل متعدد الأنماط وخصوصاً في نقل الحاويات بإنشاء محطات حاويات وتجهيز ها.

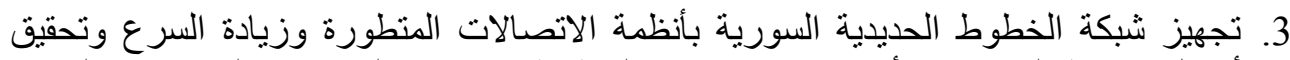

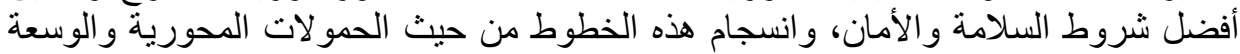

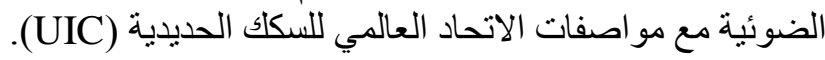

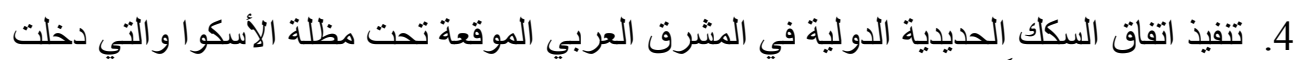

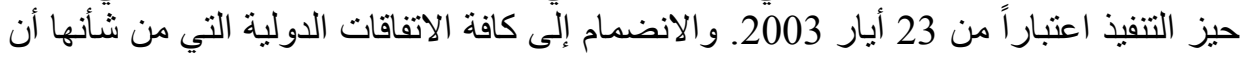
تزيد من فاعلية الخطوط الحديدية السورية. 
مجلة العلوم الهندسية - العدد السابع - ديسمبر 2014

5. تطوير أسطول السكك الحديدية السورية بما في ذلك الأدوات المحركة والمتحركة وشاحنات الحاويات لتلبية منطلبات النقل الداخلي و الإقليمي و الدولي و العابر.

6. العمل على رفع سوية العاملين في هذا المجال تقنياً وعلمياً وإدارياً وتسويقياً.

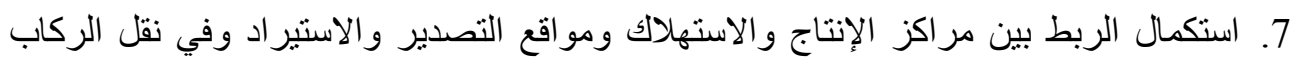

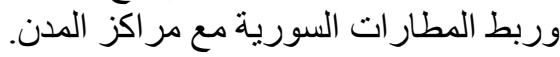

8. استغلال المزايا الإيجابية لنمط النقل السككي في نقل الحجوم الكبيرة بتوفير الطاقة والحد من

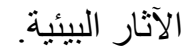

من هنا يجب النظر على دور الخطوط الحديدية السورية من منظار دولي و إقليمي لا من منظار

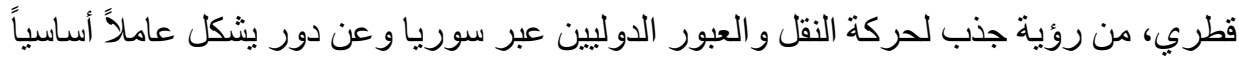
محفز اً لزيادة التبادل التجاري العربي البيني وحاملاً لهذا التبادل، وكذللك الدولي العابر لسورئ لسوريا

وبهذا فإن هناك من الدلائل ما يشير إلى أن السكك الحديدية تتمتع بالميزات النسبية التي ترشحها

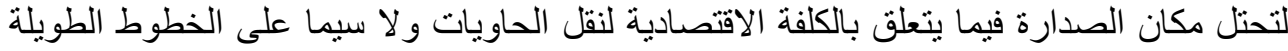

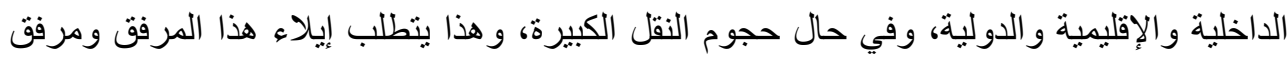

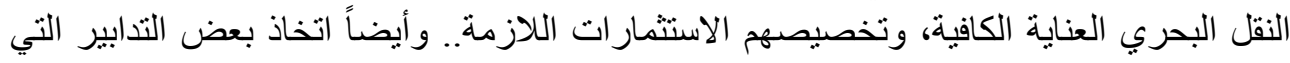

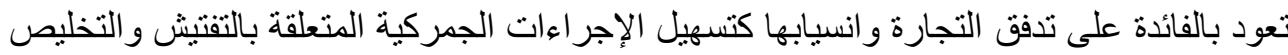

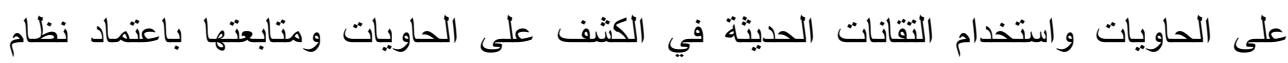

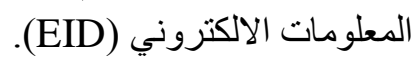

$$
\text { سادساً: المراجع }
$$

1- د. جندب زعرور د. محمد هاجم الوادي د. ابراهيم عميرة د. شفيق داؤد. هندسة السكك

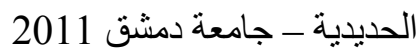

2- د. صيدناوي د. محمد هاجم الو ادي. هندسة السكك الحديدية جامعة دمشق 1998. 3- مجلة جامعة دمشق للهندسة المدنية أعوام 2005 _ 2011 دمثنق. 4- مجلة السكك و النقل المديني الدولية R J أعداد أعوام 2005 _ 2011 ل لندن. 5- مجلة الإتحاد العربي للسكك الحديديةأعداد أعوام 2000 - 2011 لب. 1- تاريخ النقل في سوريا إعداد خالد عمر كيكي مستشار سابق. 2- الإنجاز ات و المبادرات للمؤسسة العامة للخطوط الحديدية السورية 2000 2010

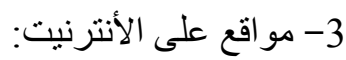
- موقع وزارة النقل سي 


$$
\begin{aligned}
& \text { - موقع المؤسسة العامة للخطوط الحديدية السورية }
\end{aligned}
$$

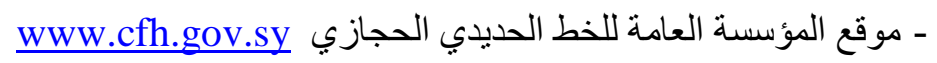

$$
\begin{aligned}
& \text { 4- تقارير ومقالات عن المؤسسات المعنية بالخطوط الحديدية. } \\
& \text { 5- در اسة شركة لويس برغر (المجلد رقم } 3 \text {, المجلد رقم 5) } \\
& \text { 6- أيوب، سميرة إبر اهيم، دار الجامعة الجديدة، الإسكندرية، 2002، ص269. } \\
& \text { 7- يوسف، محمد محمود و آخرون، المنظمة العربية للتنمية الإدارية، القاهرة، 2003، ص209. } \\
& \text { 8- المشوقي، حمد سليمان، دار الفكر العربي، القاهرة، 2003، ص310 } \\
& \text { 9- ديوب، محمد عباس. مبادئ التسويق. كلية الاقتصاد، جامعة تشرين، 2005، صن صن } \\
& \text { 10- منشور ات المكتب المركزي للاحصـاء الجمهورية العربية السورية، دمشق، الاعوام } 2000 \text { ــ } \\
& .2010 \\
& \text { 11- تقرير مؤسسة الخطوط الحديدية السورية للاعو ام } 2006 \text { - } 2010 \\
& \text { 12- مجلة جامعة تشرين للار اسات و البحوث العلمية ـ ـ سلسلة العلوم الهندسية المجلد (28) العدد } \\
& 2006 \text { (2) } \\
& \text { 13- وحدة التحديث المؤسساتي و القطاعي (حزمة المهام wp10) التقارير النهائية } \\
& \text { Institutional and Sector Modernisation Facility (ISMF) } \\
& \text { وزارة النقل(MoT) Ministry of Transport } \\
& \text { مشروع النقل المتعدد الأنماط Multi-Modal Transport Project }
\end{aligned}
$$

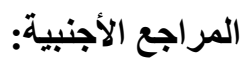

1- LIEB, R. transportation Virginia, U.S.A, 1988. Chap.7

2- JOHN R. MAYER "transport demand-the basic from work" hardwood publishers, 1997.

3-GUY, S. \&VICTOR, T-towards, social adjustment- UN.ILO, Genev, 1997. 